\title{
Retardation of conditioned excitation following operational inhibitory blocking
}

\author{
TODD R. SCHACHTMAN, LOUIS D. MATZEL, and RALPH R. MILLER \\ State University of New York at Binghamton, Binghamton, New York
}

\begin{abstract}
Water-deprived adult rats were used in a conditioned-suppression-of-licking procedure to determine the effect of inhibitory training with a novel stimulus trained in simultaneous compound with a previously established conditioned inhibitor. This procedure constitutes an inhibitory analogue to the excitatory blocking procedure in classical conditioning. The conditioned-inhibition training consisted of either explicitly unpaired CS and US presentations or negative contingency training, in which the likelihood of the US was greater in the absence than in the presence of the CS, but the CS and the US were occasionally paired. To assess conditioned inhibition, a retardation test was used, and comparable retardation was obtained for subjects that were administered the blocking treatment and control subjects given similar conditioned-inhibition training with a compound stimulus in which the nontarget element was not previously established as a conditioned inhibitor.
\end{abstract}

Conditioned inhibition (CI) has typically been viewed as an associative state that is the diametric opposite of conditioned excitation (CE). As a case in point, Rescorla and Wagner (1972) posited that CE was based on a positive association between a conditioned stimulus (CS) and an unconditioned stimulus (US), and that $\mathrm{CI}$ was based on a negative association between a CS and a US. According to this model, the principles of acquisition, extinction, and other Pavlovian conditioning phenomena apply equally to $\mathrm{CE}$ and $\mathrm{CI}$. For example, blocking of excitatory acquisition is predicted when the target $\mathrm{CS}$ is paired with the US in the presence of a CS that was previously made excitatory through pairings with the US. Correspondingly, blocking of $\mathrm{CI}$ should occur if inhibitory training of the target CS occurs in the presence of a CS that previously was made a conditioned inhibitor.

There are numerous reports of excitatory blocking in classical conditioning (see, e.g., Mackintosh, 1978), but support for the occurrence of inhibitory blocking-that is, interference with inhibitory conditioning owing to the presence of a previously trained inhibitory stimuluscomes from a single study. Suiter and LoLordo (1971) reported blocking of $\mathrm{CI}$ using a barpress-suppression preparation and an explicitly unpaired CI training procedure (i.e., the CS occurred in the absence of a regularly

\footnotetext{
Support for this research was provided by NIMH Grant 33881 and NSF Grant BNS 86-00755 to Ralph R. Miller. Preparation of the manuscript was supported by a UK Science and Engineering Research Council Grant to Geoffrey Hall. We thank A. Brown-Su, E. Damianopoulos, D. Payne, and N. E. Spear for their helpful comments regarding this research and Cindy O'Keefe and Fay McDonald for their secretarial assistance. Correspondence should be addressed to Todd $\mathbf{R}$. Schachtman, Division of Behavioral and Psychosocial Medicine, Department of Psychiatry, University of Rochester Medical Center, Rochester, NY 14642.
}

occurring unsignaled footshock). However, they failed to provide evidence showing that inhibitory pretraining of the CS later employed as the "blocking" stimulus was sufficient to yield $\mathrm{Cl}$ as assessed on retardation and summation tests, which are generally considered necessary for the demonstration of CI (see Hearst, 1972; Rescorla, 1969b). Rather, Suiter and LoLordo demonstrated only that the presumably pretrained stimulus elevated barpress response rates in the presence of presumably excitatory contextual cues relative to the barpress rate in its absence-that is, a summation test was performed that was somewhat unconventional in that the "known" excitor was the context and was not initiated or terminated with the putative inhibitor during the summation test. Moreover, blocking of $\mathrm{CI}$ was assessed only with a retardation test; there was no conventional summation test after CI training with the compound stimuli that used a discrete $\mathrm{CS}$ as the known excitor. Adding to the uncertainty surrounding blocking of CI, Moore and Stickney (1985) were unable to obtain the effect using rabbits in a nictitating membrane preparation.

In the present experiment, we sought to examine the consequences of a blocking procedure on inhibitory conditioning by using a retardation test. On the basis of Suiter and LoLordo's (1971) results and the Rescorla-Wagner (1972) model, we anticipated greater excitatory responding to the target CS (i.e., less retardation for the "blocked" stimulus) in the blocking groups than in the blocking control groups. The experiment employed a training regimen that had previously been demonstrated to produce $\mathrm{CI}$ as measured by both summation and retardation tests (Schachtman, Brown, Gordon, Catterson, \& Miller, 1987). We planned to initially administer a retardation test like Suiter and LoLordo's and, if blocking of CI was suggested, to follow that test with a study that employed a summation test. 
All of the subjects in the present study were first exposed to each of three distinctly different contexts (A, B, and $\mathrm{C}$ ). Then, in Phase 1, some animals (the blocking groups) were given negative-contingency training in Context $\mathrm{A}$, with a white noise as the CS and footshock as the US, using the exact procedure and parameters of Schachtman et al. (1987). In their Experiment 1, Schachtman et al. gave rats, in each of four 60-min sessions of $\mathrm{Cl}$ training, eight white-noise presentations, two of which were reinforced with footshock [i.e., $P(\mathrm{US} /$ noise $)=.25$ ], as well as 42 unsignaled footshocks $[P(\mathrm{US}) /$ no-CS $)=$ $.81]$. (The latter probability was based on the conceptual division of the session time into units equal in length to that of the CS.) They tested their subjects in a neutral context and found that the noise passed a summation test as well as a retardation test in which excitatory responding was assessed following 6 noise-shock retardation-test pairings. In the present study, we decided, on the basis of preliminary studies undertaken to determine the number of pairings needed to obtain a sensitive retardation test free of floor and ceiling effects, to give 16 , rather than 6, retardation-test pairings of the added element (target CS) and footshock. Following Suiter and LoLordo's (1971) precedent, other animals (the blocking control groups) were given equivalent footshocks in Context A without CS presentations. During Phase 2, all blocking and blocking control groups received CI training in Context $\mathrm{A}$ identical to that experienced by the blocking groups during Phase 1, except that the CS was a compound stimulus consisting of a click train and the white noise. In Phase 3, all subjects received click train-footshock pairings in Context $\mathrm{A}$ to assess retardation. Finally, in Phase 4, all animals were tested in Context B with the click train. The testing occurred in Context $B$ because its associative neutrality ensured that responding to the clicks would not be influenced by associative summation between the clicks and the test context.

\section{METHOD}

\section{Subjects}

The subjects were naive adult Sprague-Dawley-derived rats bred in our colony. There were 55 males and 55 females. The body weights of the males were $252-397 \mathrm{~g}$, and those of the females were $187-281 \mathrm{~g}$. The rats were individually housed in wire-mesh cages in a vivarium and maintained on a 16:8-h light:dark cycle. The experimental sessions occurred near the middle of the light cycle. The subjects had continuous access to Purina Lab Chow in the home cage, whereas water access was limited to $10 \mathrm{~min} /$ day within $1 \mathrm{~h}$ following each experimental session. The water-deprivation schedule was gradually imposed, starting 1 week prior to the beginning of the study.

\section{Apparatus}

Three highly dissimilar contexts were used in the study. One context (of which there were 6 copies) was a clear Plexiglas box measuring $22.75 \mathrm{~cm}$ long $\times 8.25 \mathrm{~cm}$ wide $\times 13 \mathrm{~cm}$ high with a floor of $0.48-\mathrm{cm}$-diam stainless steel rods oriented parallel to the width of the chamber, separated by $1.90 \mathrm{~cm}$ center-to-center, and electronically shorted to ground except during conditioning, when they were connected by NE- 2 neon bulbs. The environmental enclosures housing these clear chambers were illuminated by a $7-\mathrm{W}$ (nominal at $120 \mathrm{~V}$ ac) white houselight driven at $57 \mathrm{~V} \mathrm{ac}$. A ventilation fan mounted on the enclosure produced a $70-\mathrm{dB}(\mathrm{C})$ (re. SPL) background noise level.

A second context (of which there were 6 copies) consisted of a $30-\mathrm{cm}-$ long box with a truncated V shape. The chamber had stain less steel side walls, black Plexiglas end walls, and a clear Plexiglas ceiling. It measured $28 \mathrm{~cm}$ in height and $21.5 \mathrm{~cm}$ in width at the top, and tapered down to $5.25 \mathrm{~cm}$ in width at the bottom. The floor was constructed of two parallel stainless steel plates that were $2 \mathrm{~cm}$ wide and separated by a $1.25-\mathrm{cm}$ gap. Each of the V-shaped contexts had its own isolation enclosure with a background noise level of $70 \mathrm{~dB}(\mathrm{C})$. The interior of each enclosure was dimly illuminated by a $7-\mathrm{W}$ (nominal at $120 \mathrm{~V}$ ac) white light driven at $57 \mathrm{~V} \mathrm{ac}$, with light entering the $\mathrm{V}$-shaped chamber through the clear Plexiglas ceiling.

Both of these types of contexts had a 1.6-cm-diam hole centered in an end wall $3.5 \mathrm{~cm}$ above the floor, which allowed the insertion of a water-filled lick tube. Standard lickometer circuits were used to monitor licking responses. A constant-current footshock could be delivered through the floors of these chambers by a high-voltage transformer in series with a $1-\mathrm{M} \Omega$ resistor and the floor grids. The footshock wiring prohibited the assessment of licking during the sessions in which footshock was administered. The environmental chests housing these two chamber types each contained two $45-\Omega$ speakers mounted on the end wall of the enclosures. One speaker was used to present a $3 / \mathrm{sec}$ click train that was $8 \mathrm{~dB}(\mathrm{C})$ above the background noise level. The second speaker could present a whitenoise stimulus.

The third type of chamber (of which there were 12 copies) was $50 \mathrm{~cm}$ long $\times 8.2 \mathrm{~cm}$ wide $\times 50 \mathrm{~cm}$ high. These chambers (called Context C) had side walls constructed of opaque gray Plexiglas and end walls of aluminum. The floor was made of stainless steel rods that were $0.64 \mathrm{~cm}$ in diameter, separated $1.59 \mathrm{~cm}$ center-to-center, oriented parallel to the length of the chambers, and connected by $\mathrm{NE}-2 \mathrm{H}$ neon bulbs. A $60-\mathrm{Hz}$ fortshock could be delivered through the floor of these chambers by a high-voltage transformer in series with a $1-\mathrm{M} \Omega$ resistor, the neon bulbs, and the grid floor. These chambers had no lick tube and were housed in a well-lit experimental room. A 45- $\Omega$ speaker mounted on the clear Plexiglas ceiling of each chamber was used to deliver a $3300-\mathrm{Hz}$ tone that was $15 \mathrm{~dB}(\mathrm{C})$ above the background noise level. Kasprow, Schachtman, and Miller (1987) and Schachtman et al. (1987) have demonstrated that subjects can discriminate between the three contexts when the contexts have different conditioning histories-that is, when there is little generalization among the contexts. Moreover, experiments conducted in our laboratory have demonstrated that the tone and the click train do not appreciably generalize to each other noise (Kasprow, 1982; Schachtman et al., 1987).

\section{Procedure}

On Days 1-4 of the study, the subjects were exposed to each of the three contexts for $20 \mathrm{~min}$, with water-filled lick tubes available in all but Context $C$. The subjects in each group were counterbalanced with respect to the chamber type (the clear box or the black $\mathrm{V}$-shaped chamber) in which they were initially placed on Day 1 . This context was called Context $A$; the other context containing a lick tube was called Context $B$. During this session in Context $A$, the latencies for each subject to emit Licks 0-25 and 25-50 were recorded. Following this session, the rats were immediately placed in Context $\mathrm{C}$ for $20 \mathrm{~min}$. (Exposure to Context $\mathrm{C}$ was included in anticipation of summation tests planned for subsequent experiments.) Finally, the subjects were placed in Context B for a 20 -min session. Context $B$ corresponded to a black chamber for the subjects initially exposed to a clear chamber on Day 1 , and a clear chamber for the subjects initially exposed to a black chamber. Latencies to emit the first and second 25 licks after placement in Context B were 
also recorded. Day 3 was identical to Day 1 . Days 2 and 4 of lick training were identical to Days 1 and 3 , except that the subjects were exposed to the contexts in the order B-C-A. The subjects were then pseudorandomly assigned to one of five groups $(n s=22)$, counterbalancing to the extent possible for sex, litter, type of chamber used as Context $\mathrm{A}$, and body weight.

Phase 1 training occurred on Days 5-8. On each of these days, subjects in Group PRNC-block (partial reinforcement, negative contingency-blocking condition) were placed in Context $A$ for $60 \mathrm{~min}$, during which they received eight 60 -sec presentations of white noise $3,9,18,30,34.5,42,46.5$, and $58.5 \mathrm{~min}$ into the session. Each day, two of the eight presentations were reinforced at offset with 0.7-mA, 500-msec footshock [i.e., $P($ US $/ C S)=.25$ ]. These reinforced CS trials occurred on the 1st and 4th, 2nd and 4th, 1st and 6th, and 5th and 8th CS presentations on Days 5-8, respectively. Additionally, the subjects received 1 footshock during 42 of the 5260 -sec, no-CS intervals [i.e., $P(\mathrm{US} /$ no-CS) $=.81$ ]. These footshocks occurred $55 \mathrm{sec}$ into the 60 -sec no-CS interval, rather than at the end of the interval, to prevent CS onset from immediately following shock offset. Group EU-block (explicitly unpairedblocking condition) received treatment identical to that received by Group PRNC-block, except that all CS presentations were nonreinforced; hence, this group received 42 rather than 44 footshocks. On the days that Group PRNC-block received negative contingency training, Group PRNC-control was placed in Context A for $60 \mathrm{~min}$ but received only 44 footshocks, which were identical to those presented to Group PRNC-block-that is, no CS was presented. Similarly, on the days that Group EU-block received explicitly unpaired CI training, Group EU-control was placed in Context A and received only $\mathbf{4 2}$ footshocks identical to those presented to Group EU-block. Additionally, a fifth group, Group USO (US only), was included to permit assessment of the degree of retardation in the four other groups due to all factors other than nonassociative US preexposure effects. This group received only the 44 unsignaled footshock presentations in an irrelevant context, Context $\mathrm{C}$, during each 60-min session of Phases 1 and 2 . This group controlled for any nonassociative effects of US exposure that might have occurred for the other groups; four sessions of such exposure had been shown to produce a sensitization effect (Schachtman et al., 1987, Experiment 4). Other possible control conditions for $\mathrm{CI}$ might have been used to differentiate the effects of Context A-footshock associations from other sources of retardation. However, retarded excitatory responding after $\mathrm{CI}$ training has been found to be largely the consequence of associations between the training context and the US (Schachtman et al., 1987; see also Matzel, Brown, \& Miller, 1987). That is, aside from nonassociative US exposure effects and latent inhibition, all retardation following $\mathrm{CI}$ training is determined by an association of nontarget events of the training episode with the US, which influences the target $\mathrm{CS}$ by affecting learning about the CS (e.g., blocking by context) or performance to the CS (e.g., by comparator mechanisms; see Miller \& Schachtman, 1985, and discussion below). All subjects remained in the home cage on Days 9-15 so that the present procedure would be similar to that of tentatively planned experiments in which Days 9-16 would be used to extinguish training context-footshock associations.

Phase 2 conditioning occurred on Days 17, 18, 22, and 23. On each of these days, all subjects in Groups PRNC-block and PRNC-control received CI training that was identical to the Phase 1 training for Group PRNC-block, except that the CS was a simultaneous compound of the white noise and the click train. Similarly, all subjects in Groups EU-block and EU-control received training identical to that received by Group EU-block in Phase 1, except that the white noise and click train compound served as the CS. In Phase 2, Group USO received, in Context C, 4 more days of the footshock-only treatment that had been administered on Days 5-8.

Phase 3 tone training occurred on Days 19-21. On Day 19, all subjects were given a 60 -min session in Context $C$ in the absence of nominal stimulus presentations, to allow for adaptation to the enclosure. On Days 20 and 21 , subjects were placed in Context $C$ for $60 \mathrm{~min}$ and received four daily $5-\mathrm{sec}, 3300-\mathrm{Hz}, 15-\mathrm{dB}(\mathrm{C})$-abovebackground tone presentations reinforced at offset with 2-mA, 2-sec footshock. The trials occurred 14.5, 29.5, 44.5, and 59.5 min into the session. Tone training was included to maintain comparability with the CI training procedure used by Schachtman et al. (1987), in which Phase 3 training provided a known excitor for use during summation tests.

Phase 4 retardation-test pairings occurred on Days 24 and 25. All subjects were placed in Context $A$ for $60 \mathrm{~min}$ and received eight presentations of the 60 -sec click train reinforced at offset with 0.7-mA, 500-msec footshock. These trials were initiated 3, 9, 18 , $30,34.5,42,46.5$, and $58.5 \mathrm{~min}$ into the session. On Day 26, one 20 -min session in Context B was administered to all animals to restore baseline lick performance. Latencies to emit Licks 0-25 and 25-50 were recorded. Testing took place on Day 27. All subjects were placed in Context B, allowed to complete 25 licks, and presented with the click train upon emission of Lick 25 . Thus, all animals were drinking at the onset of the test stimulus. The click train remained on until the subjects completed 25 licks in its presence. The latency to complete 25 licks in the presence of the click train was the critical response measure. Testing in Context B prevented the training context from potentiating CS-US associations and the training context-US associations from summating with associations to the click train (Balaz, Capra, Hartl, \& Miller, 1981; Rescorla, 1985). Miller and Schachtman (1985) demonstrated that following negative contingency training, conditioned behavior indicative of $\mathrm{CI}$ is inversely related to the associative strength of the CS training context, regardless of where the subjects are tested. Latencies were transformed to $\log$ latencies to permit the use of parametric statistics. The study was conducted in three balanced replications.

\section{RESULTS AND DISCUSSION}

Three subjects from Group PRNC-control, 2 from each of Groups PRNC-block and EU-block, and 1 from Group USO were eliminated from the study due to illness or apparatus malfunction. There was no significant replication effect or interaction of this factor with other factors ( $p s>.10)$; hence, scores were collapsed over replications. Group mean latencies to emit Licks 0-25 and 25-50 on Days 4, 26, and 27 are shown in Table 1 . There were no group mean differences in latencies to emit, in Context B, Licks 0-25 on Day 4 or Licks 25-50 on Day 26 $(p s>.10)$. A significant difference among groups to emit Licks 25-50 on Day 4 occurred because Group PRNC-control took slightly longer to complete these licks $[F(4,96)=3.14, p<.05]$. Additionally, a group mean difference in latencies to emit Licks $0-25$ occurred on Day $26[F(4,99)=3.72, p<.005]$, largely because Group USO emitted 25 licks in less time (mean $=.99$ $\log \mathrm{sec})$ than the other groups $(1.45 \leq$ means $\leq 1.64$ $\log \mathrm{sec})$. This difference was no longer present on Licks $0-25$ of Day $27(F<1)$.

An analysis of variance conducted on the mean latencies to emit Licks 25-50 on Day 27 revealed a statistically significant effect of treatment $[F(4,97)=6.40, p<$ $.001]$. Planned comparisons found that all groups yielded significant $\mathrm{CI}$ as compared with Group USO $[F(1,97) \geq$ $9.13, p<.005]$. However, Group PRNC-block did not 
Table 1

Mean Lick Training, Baseline Restoration, and Test Suppression Latencies (in log sec)

\begin{tabular}{|c|c|c|c|c|}
\hline \multirow[b]{2}{*}{ Group } & \multicolumn{2}{|c|}{ Licks 0-25 } & \multicolumn{2}{|c|}{ Licks $25-50$} \\
\hline & Mean & $S E$ & Mean & $S E$ \\
\hline \multicolumn{5}{|c|}{ Day 4 (Lick Training) } \\
\hline PRNC-block & 1.07 & .11 & 0.63 & .03 \\
\hline PRNC-control & 0.96 & .07 & 0.81 & .08 \\
\hline EU-block & 0.95 & .10 & 0.65 & .04 \\
\hline EU-control & 0.87 & .09 & 0.60 & .02 \\
\hline USO & 0.75 & .08 & 0.67 & .04 \\
\hline \multicolumn{5}{|c|}{ Day 26 (Baseline Restoration) } \\
\hline PRNC-block & 1.45 & .13 & 0.94 & .11 \\
\hline PRNC-control & 1.63 & .16 & 0.70 & .06 \\
\hline EU-block & 1.58 & .18 & 0.73 & .06 \\
\hline EU-control & 1.64 & .13 & 0.76 & .06 \\
\hline USO & 0.99 & .11 & 0.94 & .14 \\
\hline \multicolumn{5}{|c|}{ Day 27 (Test)* } \\
\hline PRNC-block & 0.79 & .09 & 1.22 & .15 \\
\hline PRNC-control & 1.02 & .12 & 1.19 & .14 \\
\hline EU-block & 0.86 & .09 & 1.10 & .13 \\
\hline EU-control & 0.94 & .07 & 1.40 & .14 \\
\hline USO & 0.97 & .11 & 2.04 & .18 \\
\hline
\end{tabular}

Note-PRNC $=$ Partially reinforced negative contingency, EU $=$ explicitly unpaired, USO = US only. *The target CS was present only during the second set of 25 licks for Day 27.

differ from Group PRNC-control $(p>.10)$, and Group EU-block did not differ significantly from Group EUcontrol $(p>.10)$. Thus, no blocking of CI was observed. Moreover, the nonsignificant tendency toward a difference between Groups EU-block and EU-control was in the direction counter to blocking of CI. Additionally, the large difference between Group USO and the other groups promotes the view that the latter groups all exhibited conditioned inhibition.

This experiment used a CI training procedure that had been previously demonstrated to produce a CS capable of passing both inhibitory summation and retardation tests (Schachtman et al., 1987). Therefore, the present Phase 1 procedure resulted in a potential "blocking" CS that was truly inhibitory, whereas the previous report of inhibitory blocking failed to demonstrate that its blocking stimulus passed the conventional tests for CI (Suiter \& LoLordo, 1971). The present experiment was only one of several studies that were conducted in our laboratory in an effort to obtain inhibitory blocking. These other experiments all also failed to detect inhibitory blocking. These experiments confirmed the present finding and included the use of a light as the target CS (and the white noise as the blocking stimulus).

The present findings are consistent with the results of Moore and Stickney (1985), but are in conflict with the results of Suiter and LoLordo (1971) and predictions derived from the Rescorla-Wagner (1972) model. The source of the discrepancy between the null results reported here and by Moore and Stickney and the positive finding by Suiter and Lolordo is not clear. Moore and Stickney used the nictitating membrane response by rabbits and a
Pavlovian CI training procedure. The present study and Suiter and LoLordo's study both used conditioned suppression by rats and an explicitly unpaired CI training regimen, but Suiter and LoLordo employed suppression of barpressing for food pellets, whereas the present study used a lick-suppression task. Hence, the conflicting findings in these reports could have possibly been due to the monitoring of the response system. Alternatively, it is possible that, contrary to the Rescorla-Wagner model, inhibitory blocking does not occur. Suiter and LoLordo's results are not evidence to the contrary because they did not use standard methods to ensure that their Phase 1 training produced $\mathrm{CI}$.

A quite different view of $\mathrm{CI}$ is provided by the comparator hypothesis (Kasprow et al., 1987; Miller \& Schachtman, 1985; Schachtman et al., 1987), which posits that an animal learns an excitatory association between the CS and the US and an excitatory association between comparator stimuli and the US. Comparator stimuli are those stimuli on which the CS is superimposed during conditioning; they include the conditioning context and any cue compounded with the CS during training. The comparator hypothesis views CE and CI as categories of performance that result from a comparison of the probability of a US in the presence of the CS with the probability of the US in the presence of comparator stimuli alone. Within this framework, the greater the strength of the CS-US association relative to the strength of the comparator stimuli-US association, the greater will be the manifest CE. Conversely, the greater the comparator-US association is, relative to the CS-US association, the greater the likelihood that $\mathrm{CI}$ will be evident. The comparator hypothesis is not committed to any particular formulation as to the manner in which excitatory associations are acquired, and it does not deny the possibility of competition among cues for excitatory associative strength (i.e., excitatory blocking); however, it does obviate the need for the existence of inhibitory (negative) associations. This position is an extension of Rescorla's $(1968,1969$ a) view of CI, except that Rescorla suggested that negative associations based on the comparison of $P$ (US/CS) with $P$ (US/no-CS) are formed at the time of conditioning, whereas the comparator hypothesis, based on more recent data, assumes that inhibitory associations need not occur and that the comparison occurs at the time of testing (with "no-CS" referring to the contextual cues of the CS conditioning location, even if the test location is different from the conditioning context). According to the comparator hypothesis, inhibitory performance is due to one or more of a number of well-established conditioning effects-that is, nonassociative US habituation, latent inhibition, blocking by context, and the comparator process just described. The comparator hypothesis has been outlined as a performance rule because the comparator process, rather than influencing associative learning, presumably affects responding at test as a function of the comparison of learned associations. This process requires the subject to retain and retrieve the associative values 
of the target event and comparator stimuli at the time of testing. If testing occurs in the absence of the comparator cues, then presentation of the target event will retrieve the memory of its comparator stimuli, presumably through a target event-comparator association (see Miller \& Matzel, in press).

The central process of the comparator hypothesis fails to predict inhibitory blocking. For example, in a Clblocking study using an explicitly unpaired $\mathrm{CI}$ training procedure, the comparator hypothesis assumes that the pretrained $\operatorname{CS}(A)$ acquires little or no associative strength during Phase 1 [i.e., $P(\mathrm{US} / A)=0$ approximately], in contrast to the context, which is excitatory [i.e., $P$ (US/noCS) $>0$ ]. Within this framework, the compoundstimulus inhibitory conditioning in Phase $2(+/ A X-)$ should yield, if anything, facilitated inhibitory behavior, as compared with the behavior of control subjects lacking prior inhibitory training with $A$, because the comparator stimuli, common to $A$ and $X$, would already be excitatory (Hinson, 1982). For example, in the present CIblocking conditions which involved an explicitly unpaired CI training procedure, the control group (EU-control) received unsignaled USs in Phase 1 but no presentations of $A$. In this way, both the experimental and the control groups received comparable experience with the US during no-CS periods. Thus, similar context-US associations presumably were acquired in Phase 1 by the two groups, and in neither group should the excitatory associative strength of $X$ deviate appreciably from zero; the two groups would be equally influenced by the value of the comparator stimuli (as well as by excitatory blocking by contextual cues, latent inhibition, and US habituation/sensitization). Subsequently, both groups received identical CI training with the compound $A X$ as the CS, followed by a retardation test on $X$. Therefore, the absence of inhibitory blocking in the present experiment, albeit a null result, may be viewed as consistent with the comparator hypothesis's view of conditioned inhibition. These results are based on the present $\mathrm{CI}$ training procedure and may be specific to inhibitory treatments that produce differential excitatory conditioning of comparator stimuli (e.g., contextual cues) between $\mathrm{CI}$ and control conditions. However, according to the comparator hypothesis, if this factor were equated among groups along with the potential for latent inhibition, nonassociative US habituation, and blocking, then differences on a retardation test would not occur.

\section{REFERENCES}

Balaz, M. A., Capra, S., Hartl, P., \& Miller, R. R. (1981). Contextual potentiation of acquired behavior after devaluing direct contextUS associations. Learning \& Motivation, 12, 383-397.
Hearst, E. (1972). Some persistent problems in the analysis of conditioned inhibition. In R. A. Boakes \& M. S. Halliday (Eds.), Inhibition and learning (pp. 5-39). New York: Academic Press.

Hinson, R. E. (1982). Effects of UCS preexposure on excitatory and inhibitory rabbit eyelid conditioning: An associative effect of conditioned contextual stimuli. Joumal of Experimental Psychology: Animal Behavior Processes, 8, 49-61.

KASPROW, W. J. (1982). Loss of associability of a previously conditioned stimulus: US specificity. Unpublished master's thesis, SUNY at Binghamton.

Kasprow, W. J., Schachtman, T. R., \& Miller, R. R. (1987). The comparator hypothesis of conditioned response generation: Manifest conditioned excitation and inhibition as a function of differences in excitatory strength of CS and conditioning context at the time of testing. Joumal of Experimental Psychology: Animal Behavior Processes, 13, 395-406.

MACKINTOSH, N. J. (1978). Cognitive or associative theories of conditioning: Implications of an analysis of blocking. In S. H. Hulse, H. Fowler, \& W. K. Honig (Eds.), Cognitive processes in animal behavior (pp. 155-176). Hillsdale, NJ: Erlbaum.

Matzel, L. D., Brown, A. M., \& Miller, R. R. (1987). Associative effects of US preexposure: Modulation of conditioned responding by an excitatory training context. Journal of Experimental Psychology: Animal Behavior Processes, 13, 65-72.

Miller, R. R., \& MATZEL, L. D. (in press). Contingency and relative associative strength. In S. B. Klein \& R. R. Mowrer (Eds.), Contemporary learning theories. Hillsdale, NJ: Erlbaum.

Miller, R. R., \& Schachtman, T. R. (1985). Conditioning context as an associative baseline: Implications for response generation and the nature of conditioned inhibition. In R. R. Miller \& N. E. Spear (Eds.), Information processing in animals: Conditioned inhibition (pp. 51-88). Hillsdale, NJ: Erlbaum.

MOORE, J. W., \& STICKNEY, K. J. (1985). Antiassociations: Conditioned inhibition in attentional-associative networks. In R. R. Miller \& N. E. Spear (Eds.), Information processing in animals: Conditioned inhibition (pp. 209-232). Hillsdale, NJ: Erlbaum.

Rescorla, R. A. (1968). Probability of shock in the presence and absence of CS in fear conditioning. Journal of Comparative \& Physiological Psychology, 66, 1-5.

REsCORLA, R. A. (1969a). Conditioned inhibition of fear resulting from negative CS-US contingencies. Journal of Comparative \& Physiological Psychology, 67, 504-509.

Rescorla, R. A. (1969b). Pavlovian conditioned inhibition. Psychological Bulletin, 72, 77-81.

Rescorla, R. A. (1985). Conditioned inhibition and facilitation. In R. R. Miller \& N. E. Spear (Eds.), Information processing in animals: Conditioned inhibition (pp. 299-326). Hillsdale, NJ: Erlbaum.

Rescorla, R. A., \& Wagner, A. R. (1972). A theory of Pavlovian conditioning: Variations in the effectiveness of reinforcement and nonreinforcement. In A. H. Black \& W. F. Prokasy (Eds.), Classical conditioning II: Current research and theory (pp. 65-99). New York: Appleton-Century-Crofts.

Schachtman, T. R., Brown, A. M., Gordon, E. L., Catterson, D. A., \& MiLLER, R. R. (1987). Mechanisms underlying retarded emergence of conditioned responding following inhibitory training: Evidence for the comparator hypothesis. Joumal of Experimental Psychology: Animal Behavior Processes, 13, 310-322.

SuITER, R. D., \& LoLoRdo, V. M. (1971). Blocking of inhibitory Pavlovian conditioning in the conditioned emotional response procedure. Journal of Comparative \& Physiological Psychology, 76, 137-141.

(Manuscript received January 6, 1987; revision accepted for publication September 22, 1987.) 